\title{
Nursing diagnosis "impaired walking" in elderly patients: integrative literature review
}

\author{
Diagnóstico de enfermagem "deambulação prejudicada" no paciente idoso: \\ revisão integrativa da literatura
}

Diagnóstico de enfermería "deterioro de la deambulación" en el anciano: revisión integradora de la literatura

\author{
Cristina Maria Alves Marques-Vieira ${ }^{a}$ \\ Luís Manuel Mota de Sousab \\ João Filipe de Matos Machado Cariasc \\ Sílvia Maria Alves Caldeira ${ }^{d}$
}

\begin{abstract}
The impaired walking nursing diagnosis has been included in NANDA International classification taxonomy in 1998, and this review aims to identify the defining characteristics and related factors in elderly patients in recent literature. Integrative literature review based on the following guiding question: Are there more defining characteristics and factors related to the nursing diagnosis impaired walking than those included in NANDA International classification taxonomy in elderly patients? Search conducted in 2007-2013 on international and Portuguese databases. Sample composed of 15 papers. Among the 6 defining characteristics classified at NANDA International, 3 were identified in the search results, but 13 were not included in the classification. Regarding the 14 related factors that are classified, 9 were identified in the sample and 12 were not included in the NANDA International taxonomy. This review allowed the identification of new elements not included in NANDA International Taxonomy and may contribute to the development of taxonomy and nursing knowledge.
\end{abstract}

Keywords: Gait. Walking. Nursing diagnosis. Aged.

\section{RESUMO}

0 diagnóstico de enfermagem deambulação prejudicada integra a NANDA Internacional desde 1998, e o objetivo deste estudo é identificar as características definidoras e os fatores relacionados no paciente idoso na literatura mais atual. Revisão integrativa com a questão: existirão mais características definidoras e fatores relacionados do diagnóstico de enfermagem deambulação prejudicada, além dos que estão descritos na NANDA Internacional, que sejam específicos para o paciente idoso? Pesquisa no período 2007-2013 em bases de dados internacionais e portuguesa. Obteve-se uma amostra de 15 estudos. Entre as 6 características definidoras do diagnóstico na classificação, 3 foram identificadas nos resultados da busca na literatura, contudo, encontram-se outras 13 que não constam da classificação. Relativamente aos fatores relacionados, dos 14 classificados, 9 foram identificados na amostra e 12 não estão na classificação. Essa revisão permitiu identificar novos_elementos que não estão classificados na NANDA Internacional e pode contribuir para o desenvolvimento da taxonomia e do conhecimento de enfermagem.

Palavras-chave: Marcha. Caminhada. Diagnóstico de enfermagem. Idoso.

\section{RESUMEN}

El diagnóstico de enfermería deterioro de la deambulación integra la NANDA Internacional desde 1998 y esta revisión tuvo como objetivo identificar las características definidoras y los factores relacionados con el paciente anciano en la literatura más actual. Revisión integrada que surgió de la pregunta: ¿existirán más características y factores relacionados de deterioro de la deambulación, además de aquellas que están descritas en la NANDA Internacional, en el paciente anciano? Búsqueda en el período 2007-2013 en las bases de datos internacionales y portuguesa. Se obtuvo una muestra de 15 estudios. Entre las 6 características de diagnóstico en la clasificación, 3 fueron identificadas 3 en los resultados de la búsqueda, pero, otras 13 no constan en la NANDA Internacional. Con relación a los factores relacionados, 9 en la muestra y 12 no están en la clasificación. Nuevos elementos fueran identificados y no están clasificadas en la NANDA Internacional, ofreciendo así aportaciones para el desarrollo de la taxonomía y del conocimiento en enfermería.

Palabras clave: Marcha. Caminata. Diagnóstico de enfermería. Anciano.
D0l: http://dx.doi.org/10.1590/1983-

1447.2015.01.48602

a Rehabilitation specialist nurse, Master in Organizational Behavior and Management, PhD in Nursing, Interdisciplinary Health Research Center, Universidade Católica Portuguesa. Lisboa, Portugal.

${ }^{b}$ Rehabilitation specialist nurse. Graduate degree in Health Management. Master in Human Resource Development Policies, PhD student in Nursing at Universidade Católica Portuguesa, Nurse at Hospital Curry Cabral and Assistant Professor at Universidade Atlântica. Lisboa, Portugal.

c Nurse at the Unit of Continuing and Palliative Care of Hospital da Luz. Lisboa, Portugal.

dNurse, Master in Bioethics, PhD in Nursing, Interdisciplinary Health Research Center, Universidade Católica Portuguesa. Lisboa, Portugal. 


\section{DINTRODUCTION}

Chronic and disabling diseases associated to increased longevity represent new challenges for Nursing. Older and sicker patients are more likely to have significant impairment of the musculoskeletal system, with consequent loss of mobility. Particularly in healthcare, the practice of physical exercises has been identified as one of the main preventive measures against the development of some chronic diseases, such as hypertension (1). Walking is a modality of physical activity that also ensures independence. It is often recommended by nurses as an effective, economic and practical way of performing physical exercises. The sooner the elderly regain the ability to walk, the faster they will become independent to perform other daily activities (2). Therefore, impaired walking may lead to social isolation and the need for family caregivers.

Impaired walking (00088) is a nursing diagnosis that has been included in NANDA International (NANDA-I) classification taxonomy since 1998. At the time of the inclusion taxonomy I was in force and the diagnosis of impaired walking (6.1.1.1.3) was included in standard 6 - mobility . (3). This classification was revised in 2006 and, according to taxonomy $\mathrm{II}$, the diagnosis was included in domain 4 (Activity/rest), class 2 (Activity/exercise). The current level of evidence is 2.1 , indicating that at the time of the assessment of the referred diagnosis by the Diagnostic Development Committee it consisted of the statement, definition, defining characteristics, related factors and references. It should be noted that there is scarce clinical evidence to support the level of evidence 3, related to results from clinical trials.

In NANDA-I, nursing diagnosis impaired walking (00088) is defined by the following statement: "limitation in independent physical movement, walking, by environmental factors"(4). The defining characteristics are: "impaired ability to walk uphill, impaired ability to walk downhill, impaired ability to walk on uneven surfaces, impaired ability to go up and down sidewalks, impaired ability to climb stairs and impaired ability to walk distances required to perform activities of daily living"(4). Regarding related factors, the classification includes: "limited resilience, deconditioning, pain, impaired balance, lack of knowledge, poor muscle strength, depressive mood, environmental limitations (e.g. stairs, ramps, slopes, uneven floor surfaces, unsafe obstacles, distances, lack of mobility AIDS or assistance by caregivers, immobilizers), fear of falling, obesity, cognitive impairment, musculoskeletal impairment (e.g. contractures), neuromuscular disorders and vision impairment"(4).
Also, the international classification for nursing practice (CIPE') integrates a term in the axis "to walk" (10020886), which is defined as: "to move around: movement of the body from one place to another, move the legs to take steps, ability to support the weight of the body for effective walking, at a speed ranging from slow to moderate. Walk, go up and down stairs and ramps" (5). This is a phenomenon of interest to the nursing practice, but there are few studies providing more information and clinical evidence to the diagnosis, and bringing effective benefits to the health of people receiving nursing care. Given the date of inclusion and review of the diagnosis in the classification and the need to update concepts as the basic elements of nursing knowledge, integrative literature review (ILR) was considered a suitable method for a synthesis of knowledge relevant to the topic.

The study was based on the following guiding question: Are there more defining characteristics and factors related to the nursing diagnosis impaired walking than those described in NANDA International classification taxonomy specific for elderly patients?

The general objective of this study was to identify the defining characteristics and factors related to the nursing diagnosis impaired walking (00088) in elderly patients in the current literature. The specific objectives were: Identify the clinical indicators of the nursing diagnosis impaired walking (00088) that emerged from the review; identify the factors related regarding the referred nursing diagnosis that emerged from the review; compare the results obtained with NANDA-I classification taxonomy I; check whether the defining characteristics and the related factors included in NANDA-I classification taxonomy || appear on the results of the review. In the present study, we intend to contribute to the inclusion of other defining characteristics and factors related to the existing diagnosis.

\section{METHODOLOGY}

The use of principles of evidence-based practice (EBP) emerged from the need to bring scientific evidence closer to clinical practice problems, which motivated the development of methods of integrative literature review. This method enables the research, critical assessment and synthesis of available evidence, minimizing biases and increasing the accuracy of the conclusions ${ }^{(6)}$. The ILR is a scientific method that has the same reliability as that of other research approaches, and is a resource for the construction of knowledge in nursing. Therefore, it also contributes to the development and accuracy of clinical practice, which is characterized by interventions that result in patient safety ${ }^{(7)}$. 
Integrative literature review was conducted. It consists in a research method that incorporates evidence in clinical practice and is aimed to gather and synthesize the results of primary studies in a systematic and orderly manner, to obtain valid and reliable conclusions; This investigation method has six different stages: identification of the topic and selection of the hypothesis or guiding question of the integrative review; establishment of the criteria for inclusion and exclusion of studies/sampling or literature research; definition of the information to be extracted from the selected studies/categorization of the studies; assessment of the studies included in the integrative review; interpretation of the results; and presentation of the review/synthesis of knowledge ${ }^{(8-9)}$. Under this perspective, the stages were carried out as follows: collection of scientific evidence about impaired walking in elderly patients, examination of the scientific productions about the defining characteristics, examination of scientific productions about related factors, identification of the types of studies conducted and the methodological procedures used in impaired walking of elderly patients, descriptive analysis of the results of the studies produced and critical analyses of the results obtained.

The research was conducted from January 2007 to April 2013 , because the last review of the diagnosis occurred in 2006. The inclusion criteria were: language (Portuguese,
English or Spanish); availability (full text available online); origin (national and international studies); population (elderly); with the search strategy walk* (abstract) OR gait (abstract) AND nursing diagnoses (text) AND health (text) OR disease (text).

Bibliographic research was performed from April 15 to June 15, 2013. Manual research was conducted at Library João Paulo II at Universidade Católica Portuguesa and at the Library of Escola Superior de Enfermagem of Lisboa, as well as electronic research (Open Access Scientific Repository of Portugal, platforms B-On, EBSCO Host platform and Google Scholar database).

Bibliographic references were also considered in the selection of studies relevant to the subject under review. The research was conducted by two independent reviewers for greater accuracy of the method and results. The selection of the articles in the sample was made as follows: reading of title, reading of abstract and reading of the full text. In case of disagreement, the articles passed to the next stage for full reading.

The recommendations of the Joanna Briggs Institute ${ }^{(10)}$ were considered in the classification of the levels of evidence (LE).

Charts with information on randomized controlled clinical trials, descriptive studies, case series studies and qualitative studies obtained from the Joanna Briggs Institute

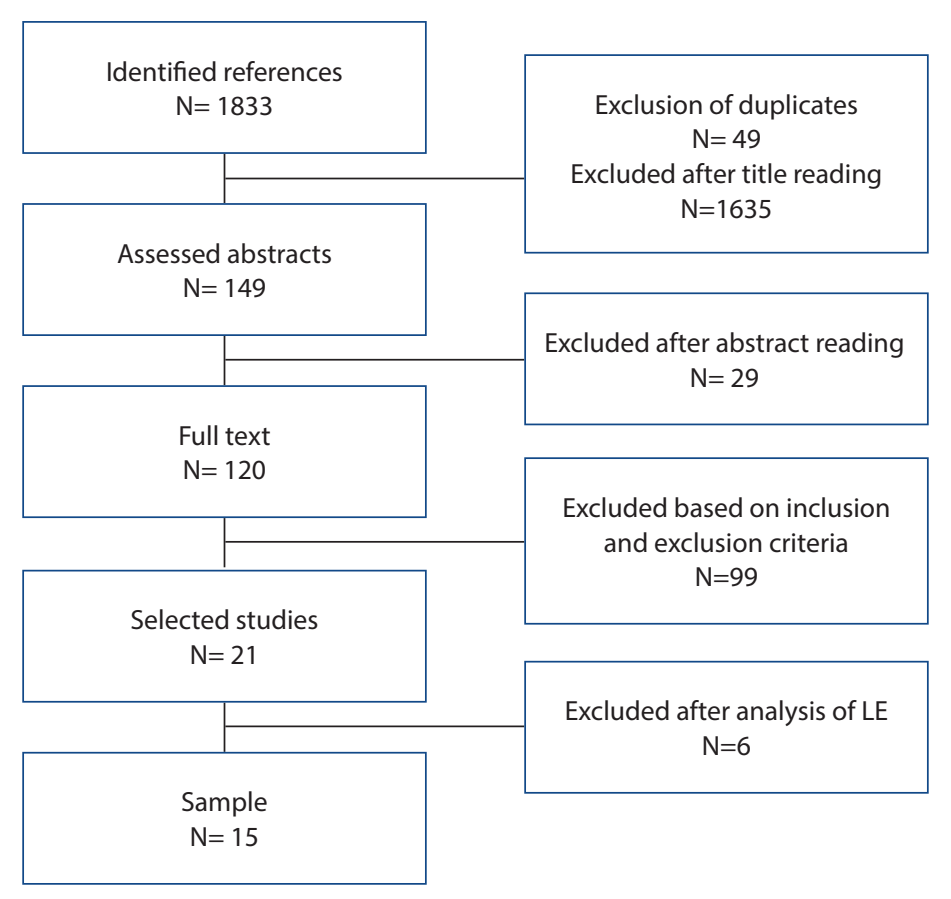

Figure 1. Mapping of the identification, analysis and selection of the results

Source: Research data, 2014.

106 Rev Gaúcha Enferm. 2015 mar;36(1):104-11. 
and translated into Portuguese were applied. They assisted in the evaluation of the criteria of feasibility suitability, significance and efficacy for inclusion of ILR articles. Following the use of these charts 6 studies were excluded (scores lower than 7) ${ }^{(10)}$. Concerning the selection of the results, 15 studies for analysis and inclusion in this review are shown in Figure 1.

In the subsequent stage, the full text of each selected study was read, for systematization of the most significant information. For this purpose, a chart was completed with data to facilitate their processing and interpretation.

Due to its nature, the present study does not involve participants. However, the intellectual property of the authors of the articles of the sample was respected, with the full and proper citation of their works.

\section{RESULTS AND DISCUSSION}

Mostresults (seven studies) were published in 2008 (2,11-16). Regarding the origin, seven studies were conducted in Brazil ${ }^{(11,13-14,16-19)}$, four studies in Portugal(2,15,20-21) and two studies in the United States of America ${ }^{(12,22)}$, one in Australia(23) and one in Japan ${ }^{(24)}$. The 15 studies selected used qualitative methodology, namely two randomized controlled clinical trials ${ }^{(13,15)}$, one cohort study ${ }^{(22)}$, three correlational studies ${ }^{(16,18,23)}$, eight descriptive studies ${ }^{(11-12,14,17,19-21,24)}$ and one systematic literature review without meta-analysis ${ }^{(2)}$. Of the analyzed studies, two had level of evidence $1^{(18,20)}$, four had level of evidence $3^{(14,1,22-23)}$, eight had level of evidence $4^{(11-13,15-16,19,21,24)}$, and one had level of evidence ${ }^{(2)}$. The samples of these studies ranged from 12 to 2269 participants.

This integrative literature review identified impaired walking as a diagnosis present in elderly patients ${ }^{(11-17)}$. Concerning impaired walking as a nursing diagnosis, it was specifically addressed by two studies. One study concludes that $72 \%$ of the patients were diagnosed with impaired walking (11) and in another study related to the identification of the risk of falling in elderly patients after stroke, impaired walking was identified among the related factors ${ }^{(17)}$. Regarding the defining characteristics, Okochi and collaborators assessed functionality in elderly patients based on the International Classification of Functioning, Disability and Health. The following parameters were assessed: walk with the aid of someone, walk without the need of walking AIDS, walk short distances $(<50 \mathrm{~m})$, walk short distances on even ground $(<50 \mathrm{~m})$, walk on different floors, overcome obstacles, go up and down stairs, walk inside buildings other than dwellings, in dwellings (at home or in a nursing home), walk with walking AIDS (walker, tripod, canes or wheelchair) and use of private or public motorized transport ${ }^{(24)}$. In another study, a systematic review concluded that the main clinical indicators of impaired walking were the need to resort to technical AIDS, independent walking on even floor surfaces and ability to climb stairs ${ }^{(2)}$. Clinical indicators obtained in another investigation of elderly included overcoming obstacles, carrying an object on uneven floor surfaces, while talking ${ }^{(22)}$.

Studies on factors related to impaired walking reveal that $80 \%$ of the elderly had a condition associated to osteoarthritis formation process, $46.7 \%$ are pre-obese and $21.7 \%$ are obese, and that most patients reported claudication and pain as their most frequent daily symptoms, and that they had to use technical AIDS ${ }^{(20)}$. Another study concluded that the perception of health, balance and walking speed are related to demographic data and cognitive and health levels of the participants. Participants with better health perception showed better results regarding the number of blocks walked than participants with a worse health perception ${ }^{(12)}$. In an investigation aimed to analyze spatial and temporal parameters in elderly with peripheral arterial disease and intermittent claudication, there were more smokers in the short-term treatment group, with a greater percentage of carotid artery atherosclerotic disease, as well as submission to surgical interventions. High blood pressure and coronary artery disease were the most prevalent conditions in both groups. Regarding stride length and stance, the values were similar in both groups ${ }^{(18)}$. Another study concluded that regular physical activity improves walking parameters (speed; stride length and step width; stride length and stance), regardless of the type of physical exercise performed ${ }^{(13)}$. An investigation on the occurrence of falls identified association with decreased muscle strength, physical activity, cognitive, visual and auditory deficits, as well as the use of medication. Falls were more frequent outside the home, because of external changes (existence of stairs, type of shoes, floor conditions, among others ${ }^{(14)}$. The decrease in walking speed and in muscular strength of the lower limbs is addressed in another study as the cause for changes in walking ${ }^{(15)}$.

Reduced ability to walk was found to reduce the opportunities for individuals to participate in functional physical activities necessary to perform self-care, instrumental and labor activities, leading to a greater loss of muscular strength and triggering a vicious circle of inactivity and weakness ${ }^{(19)}$. Other results demonstrate that step width and a shorter stride are directly associated to decreased balance and that fear of falling and step width have little 
influence on balance ${ }^{(23)}$. In another study it was found that regardless of the level of balance, the parameter walking speed decreased with aging in the individuals of the two study groups ${ }^{(16)}$. Women and elderly have greater functional impairment, particularly regarding walking, associated to pain, and depression also seems to be associated with pain and functionality ${ }^{(21)}$. Nineteen (19) clinical indicators/defining characteristics of impaired walking of elderly patients were identified (Chart 1).

The most frequent indicator $(n=3)$ in this review was: impaired ability to walk independently (resorts to technical AIDS). The least frequent $(n=1)$ were: impaired ability to walk distances required to perform routine activities, impaired ability to walk on level surfaces, impaired ability to walk while carrying something, impaired ability to walk and talk, impaired ability to climb down stairs, impaired ability to walk inside dwellings, Impaired ability to walk inside buildings other than dwellings, Impaired ability to use private or public motorized transport and Impaired ability related to stride stance. Among the defining characteristics not described in NANDA-I, the most frequent was also: impaired ability to walk independently (resort to technical AIDS) $(n=3)$.

Although the study population is formed by elderly, these results are consistent with the three defining characteristics (out of a total of six) of impaired walking classified into NANDA-I. That is, the defining characteristics found in the results and present in the classification are: impaired ability to go up and down stairs ( $n=2)$, impaired, impaired ability to walk on irregular floor surfaces $(n=2)$ and impaired ability to walk distances required to perform routine activities $(n=1)$. Other indicators not described in NANDA-I were identified, as follows: impaired ability to walk independently (resort to technical AIDS) $(n=3)$, impaired ability associated to walking speed ( $n=2)$, to overcome obstacles (walk around, climb over) $(n=2)$, to width and length of steps $(n=2)$, to walk independently $(n=2)$, walk on level surfaces $(n=1)$, walk while carrying things $(n=1)$, walk while talking

\begin{tabular}{|c|c|c|}
\hline Defining Characteristics & $\mathbf{n}$ & $\begin{array}{c}\text { NANDA-I } \\
(2012)\end{array}$ \\
\hline Impaired ability to walk independently (resort to technical AIDS) ${ }^{(11-13)}$ & 3 & \\
\hline Impaired ability to climb stairs ${ }^{(12,17)}$ & 2 & $\sqrt{ }$ \\
\hline Impaired ability to walk on irregular floor surfaces ${ }^{(11,24)}$ & 2 & $\sqrt{ }$ \\
\hline Impaired ability associated to walking speed $(14,19)$ & 2 & \\
\hline Impaired ability to overcome obstacles (walk around, climb over) ${ }^{(11,24)}$ & 2 & \\
\hline Impaired ability related to width and length of steps $s^{(14,24)}$ & 2 & \\
\hline Impaired ability to walk independently ${ }^{(12)}\left[\right.$ need help from others $\left.{ }^{(11)}\right]$ & 2 & \\
\hline Impaired ability to walk distances required to perform routine activities ${ }^{(11)}$ & 1 & $\sqrt{ }$ \\
\hline Impaired ability to walk on level surfaces ${ }^{(12)}$ & 1 & \\
\hline Impaired ability to walk while carrying something ${ }^{(24)}$ & 1 & \\
\hline Impaired ability to walk and talk ${ }^{(24)}$ & 1 & \\
\hline Impaired ability to climb down stairs ${ }^{(11)}$ & 1 & \\
\hline Impaired ability to walk inside dwellings ${ }^{(11)}$ & 1 & \\
\hline Impaired ability to walk inside buildings other than dwellings ${ }^{(11)}$ & 1 & \\
\hline Impaired ability to use private or public motorized transport ${ }^{(11)}$ & 1 & \\
\hline Impaired ability related to stride stance ${ }^{(14)}$ & 1 & \\
\hline Impaired ability to go up and down sidewalks & & $\sqrt{ }$ \\
\hline Impaired ability to walk uphill & & $\sqrt{ }$ \\
\hline Impaired ability to walk downhill & & $\sqrt{ }$ \\
\hline
\end{tabular}

Chart 1. Comparative summary of the defining characteristics found in Integrative Literature Review and NANDA Internacional, Lisboa, 2014.

Source: Research data, 2014 


\begin{tabular}{|c|c|c|}
\hline Related Factors & $\mathbf{n}$ & NANDA-I \\
\hline Walking speed ${ }^{(14,18-20,23)}$ & 5 & \\
\hline Poor muscle strength ${ }^{(15-16,23)}$ & 3 & $\sqrt{ }$ \\
\hline Stride length and stance ${ }^{(14,20-21)}$ & 3 & \\
\hline Pain ${ }^{(2,17)}$ & 2 & $\sqrt{ }$ \\
\hline Impaired balance ${ }^{(18-19)}$ & 2 & $\sqrt{ }$ \\
\hline Cognitive impairment ${ }^{(15)}$ & 1 & $\sqrt{ }$ \\
\hline Depressive mood(2) & 1 & $\sqrt{ }$ \\
\hline Environmental limitations ${ }^{(15)}$ & 1 & $\sqrt{ }$ \\
\hline Fear of falling ${ }^{(21)}$ & 1 & $\sqrt{ }$ \\
\hline Impaired vision ${ }^{(15)}$ & 1 & $\sqrt{ }$ \\
\hline Obesity $^{(17)}$ & 1 & $\sqrt{ }$ \\
\hline Osteoarticular loss ${ }^{(17)}$ & 1 & \\
\hline Excessive slimness ${ }^{(17)}$ & 1 & \\
\hline History of falls $s^{(19)}$ & 1 & \\
\hline Impaired health ${ }^{(19)}$ & 1 & \\
\hline Spatial and temporal parameters affected ${ }^{(20)}$ & 1 & \\
\hline Cardiovascular pathologies ${ }^{(20)}$ & 1 & \\
\hline Claudication $^{(17)}$ & 1 & \\
\hline Submissão a intervenções cirúrgicas ${ }^{(20)}$ & 1 & \\
\hline Auditory deficits(15) & 1 & \\
\hline Use of a given medication ${ }^{(15)}$ & 1 & \\
\hline Deconditioning & & $\sqrt{ }$ \\
\hline Lack of knowledge & & $\sqrt{ }$ \\
\hline Limited resilience & & $\sqrt{ }$ \\
\hline Musculoskeletal damage & & $\sqrt{ }$ \\
\hline Neuromuscular impairment & & $\sqrt{ }$ \\
\hline
\end{tabular}

Chart 2. Comparative summary of related factors found in the Integrative Literature Review and NANDA Internacional, Lisboa, 2014.

Source: Research data, 2014.

$(n=1)$, climb down stairs $(n=1)$, walk inside dwellings $(n=1)$, walk inside buildings other than dwellings $(n=1)$, use private or public motorized transport $(n=1)$, and related to stride stance $(n=1)$. It should be stressed that impaired ability to go up and down stairs, impaired ability to walk uphill and impaired ability to walk downhill, described by NANDA-I, were not found in these studies. Regarding the factors that are related with impaired walking, 26 factors were identified (Chart 2).

Regarding the causes of impaired walking in elderly, the most frequent $(n=5)$ related factor in this review was "walking speed", which is not part of NANDA-I. The least frequent $(n=1)$ factors were: cognitive impairment, depressive mood, environmental limitations, fear of falling, impaired vision, obesity, osteoarticular loss, excessive slimness, history of falls, impaired health, spatial and temporal parameters affected, cardiovascular pathologies, claudication, submission to surgical interventions, auditory deficits and use of a given medication. The related factors contemplated in NANDA-I and identified in the analyzed studies are: poor muscle strength, pain, impaired balance, cognitive impairment, depressive mood, environmental limitations, fear of 
falling, impaired vision and obesity. The factors related with walking speed, stride length and stance, osteoarticular loss, excessive slimness, history of falls, impaired health, spatial and temporal parameters affected, cardiovascular pathologies, claudication, surgical interventions undergone, auditory deficits and use of a given medication are described in NANDA-I and were observed in the studies. The factors reported by NANDA-I not listed by the reviewed studies that were identified are: deconditioning, lack of knowledge, limited resilience, musculoskeletal impairment and neuromuscular impairment. Most studies recommend further studies that demonstrate the benefits of nursing interventions in elderly patients with impaired walking (2,15-16,18,20-22,24). Future studies should use significant samples and scientific designs such as randomized clinical trials or quasi-experimental studies that might contribute to increase their levels of evidence.

\section{DFINAL CONSIDERATIONS}

The results of this ILR show that the objective of this study was achieved, as new defining characteristics and factors related to the nursing diagnosis impaired walking in elderly patients that are not part of the classification were identified and, on the other hand, the diagnoses classified by NANDA-I were supported. The ILR apparently contributes to the development and updating of the defining characteristics and factors related to the nursing diagnosis impaired walking. However, one important limitation of this study concerns the inclusion criterion regarding the language because the exclusion of articles published in other languages identified here certainly limited our results. With the increase in longevity, one of the main causes of restriction of activity in the elderly is imputed to the musculo-skeletal system, which leads to changes in mobility, with serious impact on the execution of daily activities and hence on the quality of life. The clinical validation of these results would be desirable, and the findings of the present study establish the relevance of validating these indicators and etiological factors in the clinical setting. By validating the defining characteristics and related factors already included in NANDA-I, and those identified in this review, for elderly patients, the importance of these factors for the nursing diagnosis can be studied. This will contribute to the improvement of taxonomy II of NANDA-I, to practice and education in nursing, since the most significant indicators for diagnosis can be identified, and also to investigation, as the guiding question of this study can be used for other populations.

\section{Q REFERENCES}

1. Guedes NG, Lopes MVO. Exercício físico em portadores de hipertensão arterial:uma análise conceitual. Rev Gaúcha Enferm. 2010;31(2):367-74.

2. Baixinho C. Capacidade de deambulação após fractura do colo do fémur: revisão sistemática da literatura. Rev Referência. 2008;II(8):79-86.

3. North American Nurses Diagnosis Association (US). Nursing diagnoses: definitions and classification (1999-2000). Philadelphia: North American Nurses Diagnosis Association; 1999.

4. Herdman H. Diagnósticos de enfermagem da NANDA: definições e classificação (2012-2014). São Paulo: Artmed; 2012.

5. Ordem dos Enfermeiros (P0). Classificação Internacional para a Prática de Enfermagem: versão 2. Santa Maria da Feira: Lusodidacta; 2011.

6. Whittemore $R$, Knafl K. The integrative review: updated methodology. J Adv Nurs. 2005;52(5):546-53.

7. Crossetti, MGO. Revisão integrativa de pesquisa na enfermagem o rigor cientifico que the é exigido [editorial]. Rev Gaúcha Enferm. 2012;33(2):8-9.

8. Ganong LH. Integrative reviews of nursing research. Res Nurs Health. 1987;10(1):1-11.

9. Souza MT, Silva MD, Carvalho R. Revisão integrativa: o que é e como fazer? Einstein. 2010;8(1 Pt 1):102-6.

10. The Joanna Briggs Institute (AT). Joanna Briggs Institute's user manual: version 5.0 system for the unified management. Assessment and Review of Information. Adelaide: Joanna Briggs Institute; 2011.

11. Figueiredo ML, Luz MH, Brito C, Sousa S, Silva D. Diagnósticos de enfermagem no idoso acamado no domicílio. Rev Bras Enferm. 2008 jul/ago; (61):464-9.

12. Talkowski J, Brach J, Studenski S, Newman A. Impact of health perception, balance perception, fall history, balance performance and gait speed on walking activity in older adults. Phys Ther. 2008:88(12):1474-81.

13. Mastandrea L. Avaliação da deambulação em idosas ativas e sedentárias [dissertação]. Ribeirão Preto: Faculdade de Medicina de Ribeirão Preto, Universidade de São Paulo; 2008.

14. Silva T. Alteração do equilíbrio e deambulação em idosos e ocorrência de quedas [dissertação]. Ribeirão Preto: Faculdade de Medicina de Ribeirão Preto, Universidade de São Paulo; 2008.

15. Yázigi F. Efeito de três meses de destreino na capacidade funcional de idosos [dissertação]. Lisboa: Faculdade de Motricidade Humana, Universidade Técnica de Lisboa; 2008.

16. Caldas C, Abreu S. Velocidade da deambulaçãa, equilíbrio e idade: um estudo correlacional entre idosas praticantes e idosas não praticantes de um programa de exercícios terapêuticos. Rev Bras Fisioter. 2008 jul/ago;12(4):324-30.

17. Costa A, Oliveira A, Moreira R, Cavalcante T, Araujo T. Identificação do risco de quedas em idosos após acidente vascular encefálico. Esc Anna Nery. 2010 out./ dez;14(4):684-9.

18. Grams S, Damiano A, Monte F, Mandelli M, Carvalho T. Deambulação de pacientes com doença arterial obstrutiva periférica e claudicação intermitente. Rev Bras Med Esporte. 2009;15(4):255-9.

19. Mantovani E. Saúde física, indicadores antropométricos, desempenho físico e bem-estar subjetivo em idosos atendidos no ambulatório de geriatria do HC/ Unicamp [dissertação]. Campinas: Faculdade de Educação Física, Universidade Estadual de Campinas; 2007.

20. Mendes ME, Novo A, Preto L. Funcionalidade de idosos com osteoartrite. In Fernandes AS, Magalhães (P, Mata MAP, Pimentel MH, BaptistaMG, editores. Dilemas atuais e desafios futuros. Livro de atas (e-book) do I Congresso de Cuidados 
Continuados; 2012 set 28-29; Miranda do Douro, Portugal. Bragança: Escola Superior de Saúde, Instituto Politécnico de Bragança, 2012. p.99-110.

21. Silva C. Dor músculo-esquelética lombar e do membro inferior e funcionalidade [dissertação]. Aveiro: Seção Autónoma de Ciências da Saúde, Universidade de Aveiro; 2011.

22. Brach J, Perera S, Vanswearingen J, Hile E, Wert D, Studenski S. Challenging gait conditions predict 1 year decline in gait speed in older adults with apparently normal gait. Phys Ther. 2011;91(12):1857-64.
23. Menz H, Lord S, Fitzpatrick R. A structural equation model relating impaired sensorimotor function, fear of falling gait patterns in older people. Gait Posture. 2007;25(2):243-9.

24. Okochi J, Takahashi T, Takamuku K, Escorpizo R. Staging of mobility, transfer and walking functions of elderly persons based on the codes of international classification of functioning, disability and health. BMC Geriatrics. 2013;13(16):1-8.

\section{Author's address:}

Cristina Marques Vieira

Instituto de Ciências da Saúde, Universidade Católica

Portuguesa, Edifício 2, Gabinete 2505, Palma de Cima

1649-023, Lisboa, Portugal

E-mail: cristina_marques@ics.lisboa.ucp.pt
Received: 11.07.2014

Approved: 12.02.2015 